\title{
Longitudinal Myocardial Contribution to Peak Systolic Flow and Stroke Volume in the Neonatal Heart
}

\author{
HANS H. ODLAND, HENRIK BRUN, YNGVE SEJERSTED, MARIT DALEN, THOR EDVARDSEN, OLA D. SAUGSTAD, \\ AND ERIK THAULOW
}

\author{
Department of Pediatric Research [H.H.O., Y.S., M.D., O.D.S.]; Institute for Surgical Research [H.H.O., T.E.]; Department of Pediatric \\ Cardiology [H.B., E.T.], Oslo University Hospital, Rikshospitalet, University of Oslo, N-0027 Oslo, Norway
}

\begin{abstract}
Systolic longitudinal myocardial function is important for cardiac ejection. Data describing hemodynamic determinants and the time course of myocardial longitudinal contraction as measured by tissue Doppler are lacking. Ten newborn pigs were used for invasive hemodynamic investigation. Tissue Doppler assessment of the lateral part of the mitral valve annulus during systole was performed during pharmacological modulation of inotropy, cardiac pacing, and modulations of loading conditions. The strongest association was found between peak systolic velocity $\left(S^{\prime}\right)$ and peak systolic flow (PSF) and end-systolic pressure (ESP), respectively $(\beta=$ $0.09 \mathrm{~cm} / \mathrm{mL}, p<0.001$ and $\beta=-0.07 \mathrm{~cm} / \mathrm{mL}, p=0.003)$. Displacement $(D)$ was mostly influenced by stroke volume $(\mathrm{SV})(\beta=0.05$ $\mathrm{cm} / \mathrm{mL}, p<0.001)$. Ejection time, SV, ESP, maximum first derivative of pressure $\left(\mathrm{dP} / \mathrm{d} t_{\max }\right)$, and PSF were all associated with $S^{\prime}$ and $D$ under different states of hemodynamic modulation; however, the ratio between PSF and $S^{\prime}, \mathrm{SV}$, and $D$ were stable during hemodynamic modulations. Normalized cross correlations indicate that $S^{\prime}$ and $D$ follow the same trajectory as flow and SV, respectively. In conclusion, this study provides validity of accounting systolic $D$ in the long axis as the longitudinal contribution to SV and peak systolic tissue velocity as the longitudinal contribution to PSF. (Pediatr Res 70: 345-351, 2011)
\end{abstract}

$\mathrm{S}^{\mathrm{y}}$ stolic excursion and motion of the mitral valve annulus has been evaluated for myocardial function in both children and adults $(1,2)$. It is easily obtainable in most patients and has the potential of being a routine parameter for assessment of myocardial function (3). Most available data are generated on the basis of studies in adults or experimental data from mature animal studies. In children, data are being published, but validated data explaining changes that occur within and between individuals at all age groups are lacking (4).This study was designed to possibly understand the nature of longitudinal peak systolic velocity $\left(S^{\prime}\right)$ and systolic displacement $(D)$ when acting under the influence of hemodynamic changes in small individuals. Neonatal pigs were chosen because of the similarity to human neonates with regards to heart size and heart rate (HR).

Received October 29, 2010; accepted April 6, 2011

Correspondence: Hans Henrik Odland, M.D., Department of Pediatric Research, Oslo University Hospital and University of Oslo, Rikshospitalet, 0027 Oslo, Norway; e-mail: h.h.odland@medisin.uio.no

Supported by grants from the Norwegian Health Association (cardiovascular council) and the Norwegian SIDS and Stillbirth Society [H.H.O.]

\section{METHODS}

Population. Ten pigs (age 3-6 d, weight 2520-6080 g) were studied under general anesthesia. A total of 185 echocardiographic assessments were performed. Twenty (11\%) assessments were excluded mainly due to no capture during right atrial pacing, missing data file, or atrial contraction before mitral valve opening during pacing. All animals were in good health without overt clinical signs of disease. The experimental protocol was approved by the Norwegian Animal Research Authority. The animals were cared for and handled in accordance with the European Guidelines for Use of Experimental Animals.

Experimental model. The piglets were anesthetized with sevoflurane for i.v. cannulation and maintained on midazolam, fentanyl, and penthobarbital. The animals were mechanically normoventilated (fraction of inhaled oxygen $\left[\mathrm{FiO}_{2}\right] 50 \%$ ). The internal jugular vein and the carotid artery were cannulated on both sides together with the femoral vein on the right side. Placement of all catheters was done under fluoroscopic monoplane guidance. A 3-Fr micromanometer pressure catheter (Model SPR 330 Millar ${ }^{\circledR}$, Millar $^{\circledR}$ Instruments, Houston, TX, USA) was introduced through the right carotid artery and placed in the ascending aorta just above the aortic valve and replaced with a wedge catheter for occlusion of the descending aorta. A 5-Fr micromanometer pressure catheter was inserted into the right ventricle through the internal jugular vein (Model MPC-500 Millar ${ }^{\circledR}$ ). A 5-Fr combined pressure and conductance catheter (Model SPR 550-5 Millar ${ }^{\circledR}$, Millar ${ }^{\circledR}$ Instruments) was used for left ventricular pressure (LVP) and volume measurements, introduced through the left carotid artery, and calibrated in the usual fashion (5). Pressure-volume relationships were analyzed in the PVAN Ultra software (version 1.1, Millar ${ }^{\circledR}$ Instruments). Through a cannulation in the femoral vein on the right side, a 5-Fr Baxter pediatric thermodilution catheter (Model 132F5, BaxterHealthcare Corporation, USA) was introduced and positioned in the pulmonary artery. A 5-Fr end-hole Wedge Pressure catheter (Arrow International, Inc., USA) was used for vena cava inferior occlusion. A 5-Fr bipolar pace catheter was used for right atrial pacing and introduced when necessary. Pacing was done with an electrophysiology stimulator (Model 5328 Programmable Stimulator, Medtronic, USA). All pressure and volume catheters were connected to the MPVS ultra system (Millar ${ }^{\circledR}$ Instruments). Data were collected with a data acquisition system (MP150 Biopac, Biopac Systems, Inc., USA) connected to a computer running AcqKnowledge ${ }^{\circledR}$ data acquisition software (Version 3.8.2 Biopac Systems, Inc.) with online display and storage. Acquisition sample rate was set to $1000 \mathrm{~Hz}$. Volume curves and LVP curves were transformed to the first derivative of volume ( $\mathrm{dV} / \mathrm{d} t$, flow) and first derivative of pressure $(\mathrm{dP} / \mathrm{d} t)$, respectively, using the derivative function with a Blackman window and filtered with a cut-off frequency of 60 $\mathrm{Hz}$. The number of coefficients used was $n-1$. Electrocardiograms (ECGs) were acquired both from far-field three-channel ECG and from near field through the pressure-volume catheter. A signal generator was manually activated to obtain a high-voltage ECG signal to allow for synchronization of the collected data files.

Echocardiographic acquisition. Echocardiography was performed using a commercially available system (Vivid 7, GE Healthcare, Vingmed, Horten,

Abbreviations: AIC, Akaike's Information Criterion; $\boldsymbol{D}$, displacement; dP/ $\mathrm{d} t_{\max }$, maximum value of the first derivative of left ventricular pressure; $\boldsymbol{E}_{\mathbf{a}}$, effective arterial elastance; ECG, electrocardiogram; EDV, end-diastolic volume; ESP, end-systolic pressure; ESV, end-systolic volume; ET, ejection time; HR, heart rate; LVP, left ventricular pressure; PSF, peak systolic flow; $S^{\prime}$, peak systolic velocity; $\mathbf{S V}$, stroke volume 
Norway). A 7-MHz probe was chosen for imaging (Model S7, GE healthcare, Vingmed). The mean frame rate at intrinsic $\mathrm{HR}$ was $401 \mathrm{~Hz}$ (min-max; $323-491 \mathrm{~Hz}$ ). Color-coded tissue Doppler tracings were acquired with no filtering or smoothing. Raw data were transferred for off-line analyses to allow for synchronization with the simultaneous acquired hemodynamic data in the AcqKnowledge ${ }^{\circledR}$ software. In this software, the tissue velocity traces were transformed to $D$ using the integral function. For stability of the hemodynamic, comparison tracings were excluded within three beats after an extra systole. Maximum and minimum values from at least six consecutive beats were also excluded. Recordings of both tissue Doppler velocity and derived data were displayed together with the simultaneous synchronized hemodynamic data on a screen. Single representative heartbeats were chosen for analyses to allow for comparison with simultaneous hemodynamic data.

Study protocol. Tissue Doppler was done at baseline, during modulation of loading and during two different inotropic states, with infusions of, respectively, esmolol (Brevibloc, Baxter, Oslo, Norway) $500 \mu \mathrm{g} / \mathrm{kg} / \mathrm{min}$ bolus followed by an infusion of $100 \mu \mathrm{g} / \mathrm{kg} / \mathrm{min}$ with stepwise increase until $20 \%$ LVP reduction was reached, and dobutamine (Hameln, Hameln Pharma plus $\mathrm{GmbH}$, Germany) $10-20 \mu \mathrm{g} / \mathrm{kg} / \mathrm{min}$, aiming at LVP increase of $20 \%$. At each

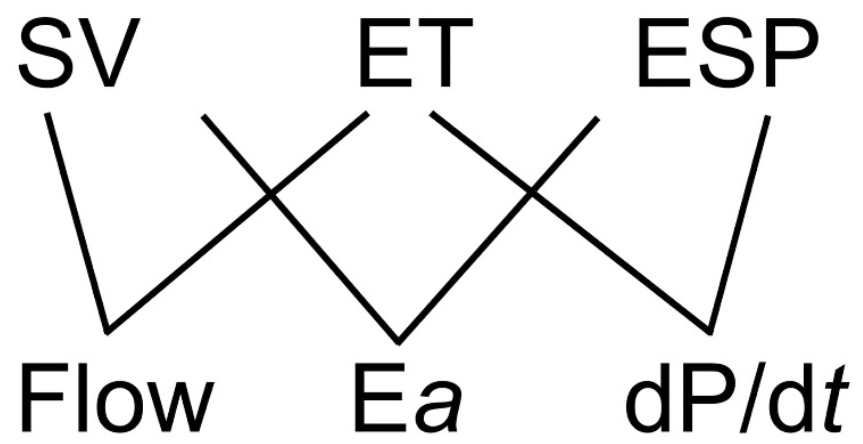

Figure 1. Multicollinearity. When combining parameters from the top row in the figure, by either multiplication or division, more complex hemodynamic parameters are formed that are closely related to the parameters in the bottom row. The top row parameters are therefore not combined with the related bottom row parameters in the multivariate model to avoid multicollinearity. stage, right atrial pacing was done to measure the effect of HR increase. All measurements were simultaneously recorded and stored. All assessments were performed during apnea.

Statistics. Values are expressed as mean \pm SEM. For analyses of repeated measurements, we used linear mixed models with structured covariance matrix (SPSS 14, SPSS Inc, Chicago, IL) (6). Appropriate covariance structure with the lowest Akaike's information criterion (AIC) was chosen. AIC is a measure of the goodness-of-fit of a statistical model with a lower AIC indicating a better fit. The proposed dependants $(Y)$, peak systolic velocity $\left(S^{\prime}\right)$, or $D$ were assessed by inclusion of one or more of the basic or derived hemodynamic determinants $(X)$ : stroke volume (SV), ejection time (ET), LVP or end-systolic pressure (ESP), peak systolic flow (PSF), effective arterial elastance $\left(\mathrm{E}_{\mathrm{a}}\right)$, and/or maximum $\mathrm{dP} / \mathrm{d} t\left(\mathrm{dP} / \mathrm{d} t_{\max }\right)$ into the linear model:

$$
Y=\beta_{0}+\beta_{1} X_{1}+\beta_{2} X_{2}+\ldots+\beta_{\mathrm{k}} X_{\mathrm{k}}+\text { random error }+ \text { fixed error }
$$

When appropriate, logarithmic transformation was done based on visual inspection of the residuals. The parameter estimate $(\beta)$ indicates the magnitude and directional change in the tissue Doppler parameter for a one-unit increase in the corresponding variable. When logarithmic transformation was done, $\beta$ indicates a one-unit increase for the transformed parameter. In multivariate analyses, models were built by including a combination of basic hemodynamic parameters and derived parameters as seen in Figure 1. Multicollinearity was assessed in a linear regression model and considered neglectable when the variance inflation factor was found to be less than 5 . However, care was taken to avoid mixing-related hemodynamic parameters in the multivariate models. Statistical differences between the groups (inotropy, $\mathrm{HR}$ ) are based on estimated marginal means with Bonferroni correction of the estimated marginal means from the linear mixed models analyses. Linear regression models used were appropriate. $p<0.05$ was considered as the level of statistical significance.

Normalized cross correlation. Adaptive template matching (AcqKnowledge ${ }^{\circledR}$ software) was used and a full cardiac cycle template was generated from the SV/flow trace for normalized cross correlation with the $D$ trace and velocity trace, respectively.

\section{RESULTS}

Relationships between peak systolic velocity and hemodynamic variables. Table 1 displays the results from multivariate linear mixed models which included the pooled data from

Table 1. Determinants of $S^{\prime}$ and $D$ in multivariate linear mixed models

\begin{tabular}{|c|c|c|c|c|}
\hline Dependent variable & Model (AIC) & Independent variables & $\beta$ & $p$ \\
\hline \multirow[t]{9}{*}{$S^{\prime}(\mathrm{cm} / \mathrm{s})$} & \multirow[t]{2}{*}{ Model1 (223) } & $E_{\mathrm{a}}(\mathrm{mm} \mathrm{Hg} / \mathrm{mL})$ & $-0.5 \pm 0.09$ & $<0.001$ \\
\hline & & $\mathrm{ET}(\mathrm{ms})$ & $-0.04 \pm 0.01$ & $<0.001$ \\
\hline & \multirow[t]{2}{*}{ Model2 (210) } & $\mathrm{SV}(\mathrm{mL})$ & $0.7 \pm 0.2$ & $<0.001$ \\
\hline & & $\mathrm{dP} / \mathrm{d} t_{\max }(\mathrm{mm} \mathrm{Hg} / \mathrm{s})$ & $2.0 \times 10^{-3} \pm 0.3 \times 10^{-3}$ & $<0.001$ \\
\hline & \multirow[t]{3}{*}{ Model3 (205) } & $\mathrm{SV}(\mathrm{mL})$ & $1.6 \pm 0.2$ & $<0.001$ \\
\hline & & $\mathrm{ET}(\mathrm{ms})$ & $-0.05 \pm 0.01$ & $<0.001$ \\
\hline & & $\operatorname{ESP}(\mathrm{mm} \mathrm{Hg} / \mathrm{s})$ & $-0.06 \pm 0.02$ & 0.003 \\
\hline & \multirow[t]{2}{*}{ Model4 (196) } & $\mathrm{PSF}(\mathrm{mL} / \mathrm{s})$ & $0.09 \pm 0.01$ & $<0.001$ \\
\hline & & $\mathrm{ESP}(\mathrm{mm} \mathrm{Hg})$ & $-0.06 \pm 0.02$ & 0.007 \\
\hline \multirow[t]{10}{*}{$D(\mathrm{~mm})$} & \multirow[t]{2}{*}{ Model1 (-34) } & $\mathrm{PSF}(\mathrm{mL} / \mathrm{s})$ & $1.4 \times 10^{-3} \pm 0.6 \times 10^{-3}$ & 0.02 \\
\hline & & $\mathrm{ESP}(\mathrm{mm} \mathrm{Hg})$ & $2.2 \times 10^{-3} \pm 1.7 \times 10^{-3}$ & NS \\
\hline & \multirow[t]{2}{*}{ Model2 (-50) } & $\mathrm{SV}(\mathrm{mL})$ & $0.06 \pm 0.9$ & $<0.001$ \\
\hline & & $\mathrm{dP} / \mathrm{d} t_{\max }(\mathrm{mm} \mathrm{Hg} / \mathrm{s})$ & $0.03 \times 10^{-3} \pm 0.02 \times 10^{-3}$ & NS \\
\hline & \multirow[t]{3}{*}{ Model3 (-52) } & $\mathrm{SV}(\mathrm{mL})$ & $0.05 \pm 0.01$ & $<0.001$ \\
\hline & & $\mathrm{ET}(\mathrm{ms})$ & $0.02 \pm 0.01$ & 0.007 \\
\hline & & $\mathrm{ESP}(\mathrm{mm} \mathrm{Hg})$ & & NS \\
\hline & \multirow{2}{*}{ Model4 (-54) } & $E_{\mathrm{a}}(\mathrm{mm} \mathrm{Hg} / \mathrm{mL})$ & $-0.02 \pm 0.004$ & 0.007 \\
\hline & & $\mathrm{ET}(\mathrm{ms})$ & $1.6 \times 10^{-3} \pm 0.5 \times 10^{-3}$ & $<0.001$ \\
\hline & Model5 (-68) & SV & $0.05 \pm 0.01$ & $<0.001$ \\
\hline
\end{tabular}

This table include pooled data from baseline, esmolol, and dobutamine at intrinsic and paced heart rate. The models are ranged by decreasing AIC which indicates a better goodness-of-fit. Values are mean \pm SEM. Model building was based on the basic hemodynamic variables SV, ET, and ESP and substitution of these by derived parameters $\left(E_{\mathrm{a}}, \mathrm{PSF}, \mathrm{dP} / \mathrm{d} t_{\max }\right)$. First, SV, ET, and ESP were included, and then to avoid multicollinearity, SV and ET were substituted with PSF, ET, and ESP with $\mathrm{dP} / \mathrm{d} t_{\max }$ and SV and ESP with $E_{\mathrm{a}}$, one at the time. If one of these parameters were found not to have significant impact on the model they were excluded, the model was retested until only parameters with significant impact remained. If more than one parameter had significant impact on the model, the one with a higher $p$-value was removed and AIC compared between the two. The models with the higher AIC (poorer goodness-of-fit) were excluded. Only parameters with significant impact on the model were included and AIC compared and the models ranged. The $\beta$ corresponds to the transformed parameter when appropriate. 
baseline, esmolol, and dobutamine challenge, at both intrinsic and paced high HR. Modeling was based on the three basic hemodynamic parameters: SV, ESP, and ET. The model that determined $S^{\prime}$ with the best fit included PSF and ESP as determinants. This model indicated that a change in PSF of 10 $\mathrm{mL} / \mathrm{s}$ would change $S^{\prime}$ by $0.9 \pm 0.1 \mathrm{~cm} / \mathrm{s}$, and a change in ESP of $10 \mathrm{~mm} \mathrm{Hg}$ would reduce $S^{\prime}$ by $0.6 \pm 0.2 \mathrm{~cm} / \mathrm{s}$. Adjusting for this relationship in a statistical model, equalized the changes caused in $S^{\prime}$ by pharmacological modulation of inotropy and atrial pacing at a higher HR. Moreover, the overall ratio between PSF and $S^{\prime}$ was $9.5 \pm 0.6 \mathrm{~mL} / \mathrm{cm}$ in the pooled data, with no differences found between the inotropic states at different HRs. On the other hand, we found an association between ESP and the $\mathrm{PSF} / S^{\prime}$ ratio $(\beta=0.11 \pm 0.04, p=$ 0.006). Adjusting for this relation did not alter the stability of this ratio toward change in inotropy and HR by pacing.

Relationship between $\mathrm{D}$ and $\boldsymbol{S V}$. The best model to determine $D$ included SV only. An increase in SV by $10 \mathrm{~mL}$ corresponded to a $5 \pm 0.7 \mathrm{~mm}$ increase in $D$. The overall ratio between $\mathrm{SV}$ and $D$ was $10.3 \pm 0.4 \mathrm{~mL} / \mathrm{cm}$ at normal and paced HR and at all inotropic states. The ratio did not change between the groups of different inotropy or HR.

Normalized cross correlation. The correlation coefficients between the flow curves and tissue Doppler velocity curves were $82 \pm 2 \%, 82 \pm 3 \%$, and $84 \pm 2 \%$ for baseline, dobutamine, and esmolol at intrinsic HR, respectively. Between SV curves and displacement curves, the correlation coefficients were $96 \pm 1 \%$ at baseline, $95 \pm 1 \%$ with dobutamine, and $95 \pm$ $1 \%$ during esmolol with intrinsic HR (Fig. 2).

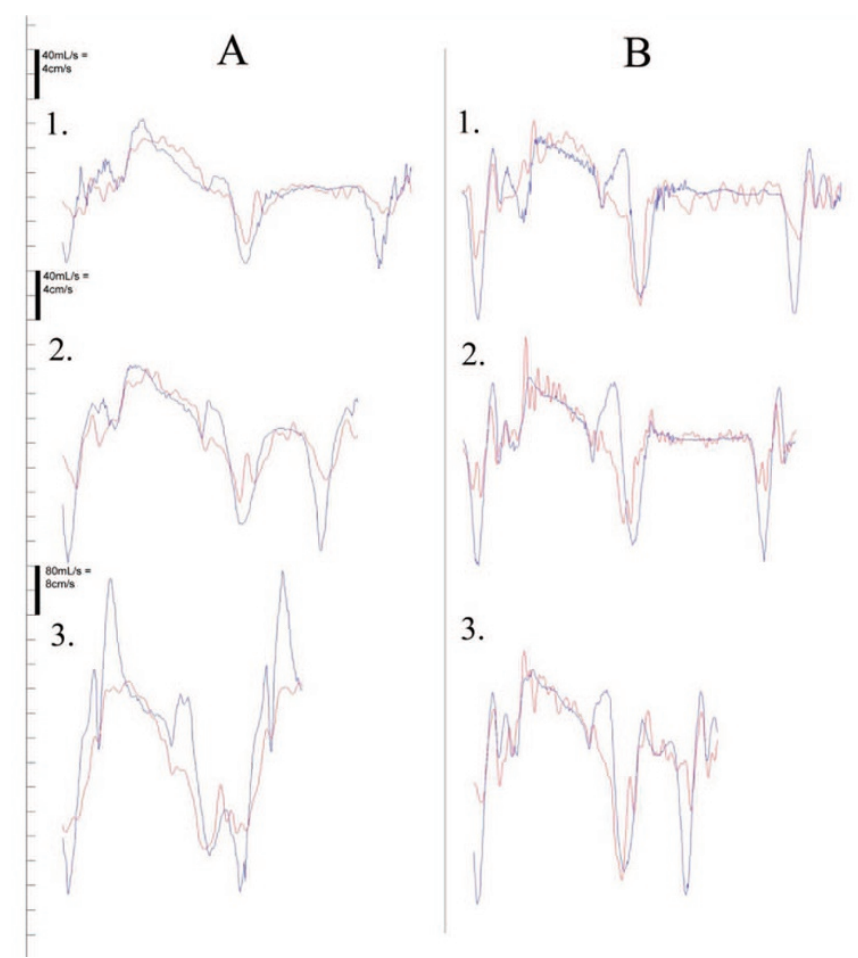

Figure 2. Comparison of simultaneous cardiac cycles showing flow by conductance measurement (red curves) and tissue Doppler derived velocity (blue curves) in two $(A$ and $B$ ) representative animals during pharmacological modulation of inotropy with intrinsic HR (1. baseline, 2. esmolol, 3. dobutamine).
Impact of heart weight on hemodynamic and tissue velocity data. Because SV was found to predicate $D$, we tested whether heart weight would be associated with $D$. At baseline and intrinsic HR, the association between heart weight and SV was $R=0.8$ and $\beta=0.04 \mathrm{~mL} / \mathrm{g}(p=0.006)$ and between heart weight and $D R=0.9$ and $\beta=0.02 \mathrm{~cm} / \mathrm{g}(p<0.001)$.

Hemodynamics. Table 2 shows the hemodynamic data at all inotropic states and HRs, except for stroke work (SW) that was only included during intrinsic HR. $E_{\text {a }}$ decreased with dobutamine, indicating a decrease in afterload. SV and pressures did not change. All parameters related to time intervals increased during positive inotropy modulation compared with baseline and esmolol. Only SW decreased during the esmolol infusion compared with baseline. ET declined with pacing at a shorter cycle length than the intrinsic rhythm and SV decreased during pacing at high HRs.

Effect of inotropic change and right atrial pacing on longitudinal function. Changes in longitudinal tissue Doppler velocity parameters and derived parameters are displayed in Table 1 and representative traces in Figure 2. $S^{\prime}$ increased during dobutamine infusion compared with baseline and esmolol infusion. This pattern did not change with pacing at a higher HR. No changes were seen in $S^{\prime}$ with pacing at each stage compared with intrinsic heart rhythm. We did not observe any changes in $D$ during the different inotropic stages, but during pacing $D$ declined at all stages compared with baseline values.

Preload modulation. Table 3 shows the effect of altering preload on hemodynamic and tissue Doppler measurements. Significant end-diastolic volume (EDV) reduction was reached at heartbeat four. This was reflected in $S^{\prime}, D, \mathrm{ET}$, and LVP. SV and $\mathrm{dP} / \mathrm{d} t_{\max }$ which reached significant reduction at heartbeat five. No changes were found in PSF. SV, ET, LVP, $\mathrm{dP} / \mathrm{d} t_{\max }$, and PSF were included in a linear mixed model to assess the association with $S^{\prime}$ and $D$. PSF and LVP were found to be the strongest determinants of $S^{\prime}\left(\beta=2.2 \times 10^{-3} \pm 0.6 \times 10^{-3}, p<0.001\right.$ and $\beta=0.02 \pm 0.01, p=0.024$, respectively), while LVP was found to be the strongest determinant of $D(\beta=0.12 \pm 0.01, p<$ 0.001). When the model was adjusted for PSF and LVP, no changes were found in $S^{\prime}$ during preload manipulation, while no changes was found in $D$ when adjusted for LVP. Table 3 shows the effect of preload reduction on the ratio between $\mathrm{SV}$ and $D$ and the ratio between PSF and $S^{\prime}$. SVID increased after the sixth heartbeat representing a reduction in EDV of $11 \%$. For the ratio $\mathrm{PSF} / S^{\prime}$, no changes were seen.

Afterload modulation. Table 4 displays the effects of occlusion of the descending aorta on hemodynamic and tissue Doppler measurements. $E_{\mathrm{a}}$ increased at heartbeat four after occlusion, while PSF, $D$, and ET did not change during the challenge. SV and $S^{\prime}$ decreased at heartbeat four and five, respectively, while end-systolic volume (ESV) and $\mathrm{dP} / \mathrm{d} t_{\max }$ increased at heartbeat four. SV, ET, PSF, $E_{\mathrm{a}}$, and $\mathrm{dP} / \mathrm{d} t_{\max }$ were included in a linear mixed model, in the same way as for preload modulation, to look at the impact on $S^{\prime}$ and $D$ during afterload challenge. PSF and $E_{\text {a }}$ were found to be the strongest determinants of $S^{\prime}(\beta=0.04 \pm$ $0.01, p<0.001$ and $(\beta=-0.05 \pm 0.01, p<0.001$, respectively), and SV was found to be the strongest determinant of $D$ $(\beta=0.05 \pm 0.01, p<0.001)$. When the model was adjusted for 
Table 2. Effects of modulation of inotropy and HR on hemodynamic parameters and tissue Doppler data

\begin{tabular}{|c|c|c|c|c|c|c|}
\hline & \multicolumn{3}{|c|}{ Intrinsic heart rate } & \multicolumn{3}{|c|}{ Paced high rate } \\
\hline & Baseline & Esmolol & Dobutamine & Baseline & Esmolol & Dobutamine \\
\hline \multicolumn{7}{|c|}{ Hemodynamic parameters } \\
\hline HR (bpm) & $158 \pm 17$ & $162 \pm 13$ & $215 \pm 17 \dagger$, 市 & $213 \pm 15 \S$ & $213 \pm 9 \S$ & $282 \pm 17 \dagger, 末, \S$ \\
\hline $\mathrm{ET}(\mathrm{ms})$ & $153 \pm 14$ & $160 \pm 11$ & $135 \pm 11 \dagger$, & $125 \pm 5 \S$ & $130 \pm 2 \S$ & $99 \pm 5 \ddagger, \S$ \\
\hline $\mathrm{SV}(\mathrm{mL})$ & $6.1 \pm 0.8$ & $5.9 \pm 0.9$ & $7.2 \pm 0.8$ & $4.5 \pm 0.8 \S$ & $5.2 \pm 0.9 \S$ & $7.1 \pm 1.7 \$, \S$ \\
\hline $\mathrm{CO}(\mathrm{mL} / \mathrm{min})$ & $933 \pm 158$ & $938 \pm 165$ & $1536 \pm 279 \dagger$,末 & $950 \pm 174$ & $1092 \pm 209$ & $2047 \pm 555 \dagger$, \\
\hline $\mathrm{PSF}(\mathrm{mL} / \mathrm{s})$ & $64 \pm 9$ & $61 \pm 9$ & $98 \pm 15 \dagger+$ & $59 \pm 9$ & $63 \pm 12$ & $110 \pm 32 \dagger+$ \\
\hline LVP (mm Hg) & $86 \pm 4$ & $77 \pm 4$ & $86 \pm 4$ & $87 \pm 5$ & $75 \pm 4$ & $83 \pm 4$ \\
\hline $\mathrm{ESP}(\mathrm{mm} \mathrm{Hg})$ & $58 \pm 3$ & $49 \pm 4$ & $52 \pm 5$ & $54 \pm 4$ & $45 \pm 2$ & $45 \pm 3$ \\
\hline $\mathrm{SW}(\mathrm{mm} \mathrm{Hg} / \mathrm{mL})$ & $503 \pm 81$ & $339 \pm 49^{*}$ & $527 \pm 77$ & & & \\
\hline$E_{\mathrm{a}}(\mathrm{mm} \mathrm{Hg} / \mathrm{mL})$ & $11 \pm 1$ & $10 \pm 1$ & $8 \pm 1 \dagger$ & $14 \pm 2$ & $11 \pm 2$ & $8 \pm 2 \dagger$ \\
\hline $\mathrm{dP} / \mathrm{d} t_{\max }(\mathrm{mm} \mathrm{Hg} / \mathrm{s})$ & $1860 \pm 205$ & $1493 \pm 135$ & $3175 \pm 249 \dagger$, & $1925 \pm 160$ & $1625 \pm 171$ & $3555 \pm 425 \dagger$, \\
\hline \multicolumn{7}{|l|}{ Tissue Doppler data } \\
\hline$S^{\prime}(\mathrm{cm} / \mathrm{s})$ & $6.8 \pm 0.6$ & $6.6 \pm 0.9$ & $10.9 \pm 1.5 \dagger$ † & $6.1 \pm 0.6$ & $6.7 \pm 1.1$ & $11.3 \pm 2.2 \dagger, \ddagger$ \\
\hline$D(\mathrm{~mm})$ & $6.0 \pm 0.5$ & $5.9 \pm 0.5$ & $6.2 \pm 0.6$ & $4.7 \pm 0.4 \S$ & $4.7 \pm 0.7 \S$ & $5.8 \pm 0.9 \S$ \\
\hline
\end{tabular}

Values are mean \pm SEM.

$* p<0.05$ baseline-esmolol.

$\dagger p<0.05$ baseline-dobutamine.

$\$ p<0.05$ esmolol-dobutamine.

$\S p<0.05$ high rate $v s$. intrinsic rate.

Table 3. Manipulation of preload by temporary balloon occlusion of vena cava inferior

\begin{tabular}{|c|c|c|c|c|c|c|c|c|}
\hline & \multicolumn{8}{|c|}{ Heartbeat number } \\
\hline & 1 & 2 & 3 & 4 & 5 & 6 & 7 & 8 \\
\hline$S^{\prime}(\mathrm{cm} / \mathrm{s})$ & $5.4 \pm 0.7$ & $5.1 \pm 0.7$ & $5.0 \pm 0.7$ & $4.7 \pm 0.6^{*}$ & $4.5 \pm 0.6 \dagger$ & $4.4 \pm 0.7 \dagger$ & $4.4 \pm 0.7 \dagger$ & $4.2 \pm 0.7 \dagger$ \\
\hline $\mathrm{PSF}(\mathrm{mL} / \mathrm{s})$ & $65 \pm 10$ & $65 \pm 10$ & $63 \pm 9$ & $65 \pm 10$ & $66 \pm 10$ & $65 \pm 9$ & $62 \pm 8$ & $61 \pm 9$ \\
\hline $\mathrm{SV}(\mathrm{mL})$ & $5.4 \pm 0.6$ & $5.2 \pm 0.6$ & $5.1 \pm 0.5$ & $5.0 \pm 0.6$ & $4.8 \pm 0.5 \dagger$ & $4.7 \pm 0.5 \dagger$ & $4.5 \pm 0.5 \dagger$ & $4.4 \pm 0.5 \dagger$ \\
\hline$D(\mathrm{~mm})$ & $4.8 \pm 0.5$ & $4.6 \pm 0.4$ & $4.2 \pm 0.4$ & $3.8 \pm 0.3^{*}$ & $3.6 \pm 0.3 \dagger$ & $3.3 \pm 0.4 \dagger$ & $3.1 \pm 0.4 \dagger$ & $3.0 \pm 0.4 \dagger$ \\
\hline $\mathrm{EDV}(\mathrm{mL})$ & $15.0 \pm 2.1$ & $14.7 \pm 2.1$ & $14.4 \pm 2.0$ & $14.1 \pm 2.0 \dagger$ & $13.7 \pm 1.9 \dagger$ & $13.4 \pm 1.9 \dagger$ & $13.2 \pm 1.8 \dagger$ & $13.1 \pm 1.9 \dagger$ \\
\hline ET (ms) & $147 \pm 17$ & $144 \pm 16$ & $141 \pm 16$ & $139 \pm 16 \dagger$ & $136 \pm 16 \dagger$ & $133 \pm 15 \dagger$ & $132 \pm 15 \dagger$ & $129 \pm 16 \dagger$ \\
\hline LVP (mm Hg) & $87 \pm 4$ & $85 \pm 4$ & $83 \pm 4$ & $81 \pm 4 \dagger$ & $79 \pm 3 \dagger$ & $77 \pm 3 \dagger$ & $75 \pm 3 \dagger$ & $73 \pm 3 \dagger$ \\
\hline $\mathrm{dP} / \mathrm{d} t_{\max }(\mathrm{mm} \mathrm{Hg} / \mathrm{s})$ & $1820 \pm 151$ & $1782 \pm 146$ & $1725 \pm 131$ & $1666 \pm 120$ & $1606 \pm 105 \dagger$ & $1563 \pm 94 \dagger$ & $1503 \pm 92 \dagger$ & $1463 \pm 86 \dagger$ \\
\hline $\mathrm{SV} / \mathrm{D}(\mathrm{mL} / \mathrm{cm})$ & $11.3 \pm 0.7$ & $11.4 \pm 0.9$ & $12.3 \pm 1.1$ & $13.0 \pm 1.0$ & $13.9 \pm 1.3$ & $15.5 \pm 1.8^{*}$ & $15.8 \pm 1.7 *$ & $15.9 \pm 2.0^{*}$ \\
\hline $\mathrm{PSF} / \mathrm{S}^{\prime}(\mathrm{mL} / \mathrm{cm})$ & $12.6 \pm 1.4$ & $13.4 \pm 1.5$ & $13.5 \pm 1.4$ & $14.1 \pm 1.6$ & $15.6 \pm 1.6$ & $16.2 \pm 1.7$ & $15.2 \pm 1.4$ & $16.1 \pm 2.0$ \\
\hline
\end{tabular}

This table shows the tissue Doppler and hemodynamic data from the first eight heartbeats after vena cava occlusion by a balloon catheter, with stroke by stroke comparison. Values are mean \pm SEM.

$* p<0.05$ compared with heartbeat one, with Bonferroni correction.

$\dagger p<0.01$ compared with heartbeat one, with Bonferroni correction.

Table 4. Manipulation of afterload by temporary balloon occlusion of the descending aorta

\begin{tabular}{|c|c|c|c|c|c|c|c|c|}
\hline & \multicolumn{8}{|c|}{ Heartbeat number } \\
\hline & 1 & 2 & 3 & 4 & 5 & 6 & 7 & 8 \\
\hline$S^{\prime}(\mathrm{cm} / \mathrm{s})$ & $6.1 \pm 0.9$ & $7.2 \pm 0.9$ & $7.0 \pm 0.9$ & $6.3 \pm 0.9$ & $6.3 \pm 0.8 \dagger$ & $6.1 \pm 0.8 \dagger$ & $5.6 \pm 0.7 \dagger$ & $5.5 \pm 0.6 \dagger$ \\
\hline $\mathrm{PSF}(\mathrm{mL} / \mathrm{s})$ & $66 \pm 14$ & $65 \pm 14$ & $64 \pm 14$ & $59 \pm 12$ & $61 \pm 13$ & $51 \pm 14$ & $61 \pm 14$ & $58 \pm 12$ \\
\hline $\mathrm{SV}(\mathrm{mL})$ & $5.7 \pm 1.0$ & $5.7 \pm 1.0$ & $5.2 \pm 1.0$ & $4.6 \pm 0.8 \dagger$ & $4.4 \pm 0.8 \dagger$ & $4.5 \pm 0.9 \dagger$ & $4.5 \pm 0.8 \dagger$ & $4.5 \pm 0.7 \dagger$ \\
\hline$D(\mathrm{~mm})$ & $5.4 \pm 0.6$ & $5.41 \pm 0.6$ & $5.1 \pm 0.5$ & $4.9 \pm 0.4$ & $4.5 \pm 0.5$ & $4.5 \pm 0.5$ & $4.5 \pm 0.4$ & $4.6 \pm 0.5$ \\
\hline ESV (mL) & $12.4 \pm 2.2$ & $12.5 \pm 2.2$ & $13.1 \pm 2.3$ & $14.0 \pm 2.4 \dagger$ & $14.5 \pm 2.8 \dagger$ & $14.9 \pm 2.8 \dagger$ & $15.2 \pm 2.5 \dagger$ & $15.3 \pm 2.5 \dagger$ \\
\hline $\mathrm{ET}(\mathrm{ms})$ & $151 \pm 13$ & $151 \pm 11$ & $152 \pm 15$ & $154 \pm 14$ & $142 \pm 8$ & $146 \pm 8$ & $160 \pm 14$ & $160 \pm 14$ \\
\hline$E_{\mathrm{a}}(\mathrm{mm} \mathrm{Hg} / \mathrm{mL})$ & $14.2 \pm 2.8$ & $13.6 \pm 2.5$ & $20.5 \pm 4.4$ & $25.4 \pm 5.2 \dagger$ & $26.7 \pm 5.5 \dagger$ & $28.5 \pm 6.6 \dagger$ & $28.3 \pm 5.3 \dagger$ & $28.3 \pm 5.9 \dagger$ \\
\hline $\mathrm{dP} / \mathrm{d} t_{\max }(\mathrm{mm} \mathrm{Hg} / \mathrm{s})$ & $1602 \pm 161$ & $1595 \pm 164$ & $1597 \pm 162$ & $1831 \pm 208^{*}$ & $1981 \pm 243 \dagger$ & $2001 \pm 242 \dagger$ & $1953 \pm 225 \dagger$ & $1933 \pm 228 \dagger$ \\
\hline $\mathrm{SV} / D(\mathrm{~mL} / \mathrm{cm})$ & $10.4 \pm 1.5$ & $10.5 \pm 1.4$ & $9.9 \pm 1.5$ & $9.0 \pm 1.2$ & $9.2 \pm 1.3$ & $9.6 \pm 1.3$ & $9.6 \pm 1.3$ & $9.7 \pm 1.2$ \\
\hline $\mathrm{PSF} / \mathrm{S}^{\prime}(\mathrm{mL} / \mathrm{cm})$ & $8.8 \pm 1.1$ & $8.6 \pm 1.1$ & $8.6 \pm 1.3$ & $9.3 \pm 1.3$ & $9.3 \pm 1.3$ & $9.4 \pm 1.4$ & $10.6 \pm 1.6$ & $10.3 \pm 1.3$ \\
\hline
\end{tabular}

This table shows the tissue Doppler and hemodynamic data from the first eight heartbeats after occlusion of the descending aorta by a balloon catheter, with stroke by stroke comparison. Values are mean \pm SEM.

$* p<0.05$ compared with heartbeat one, with Bonferroni correction.

$\dagger p<0.01$ compared with heartbeat one, with Bonferroni correction.

PSF and LVP, no changes were found in $S^{\prime}$. Similar to this, no changes were found in $D$ when the model was adjusted for SV. Afterload plays an important role for $S^{\prime}$. An increase in afterload of about $20 \%$ will reduce $S^{\prime}$ by $11 \%$, while an increase in PSF by $15 \%$ will increase $S^{\prime}$ by $15 \%$. Table 4 shows the effect of afterload increase on the ratio between $\mathrm{SV}$ and $D$ and the ratio 


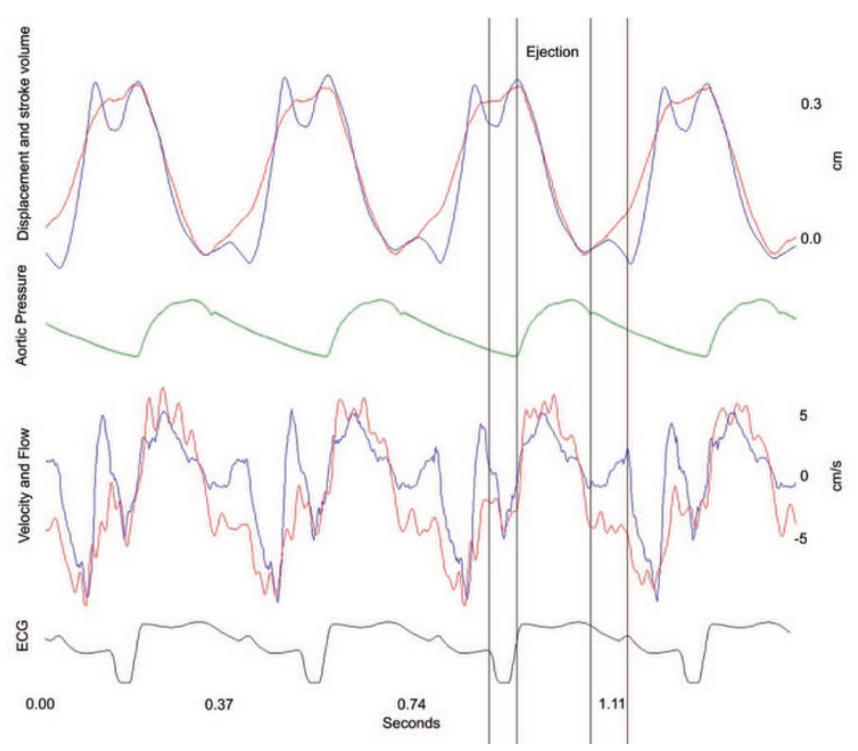

Figure 3. Representative traces from one pig at baseline. $D(\mathrm{~cm}$, blue lines upper row) and tissue velocity $(\mathrm{cm} / \mathrm{s}$, blue lines lower row) are displayed with simultaneous conductance derived volume change ( $\mathrm{mL}$, red lines upper row) and derivative of the volume change; flow $(\mathrm{mL} / \mathrm{s}$, red lines lower row). Simultaneous aortic pressure curve (green line) and ECG (black line) are displayed for comparison. The scaling between $D$ and volume is 1:12 and between tissue velocity and flow is 1:6.

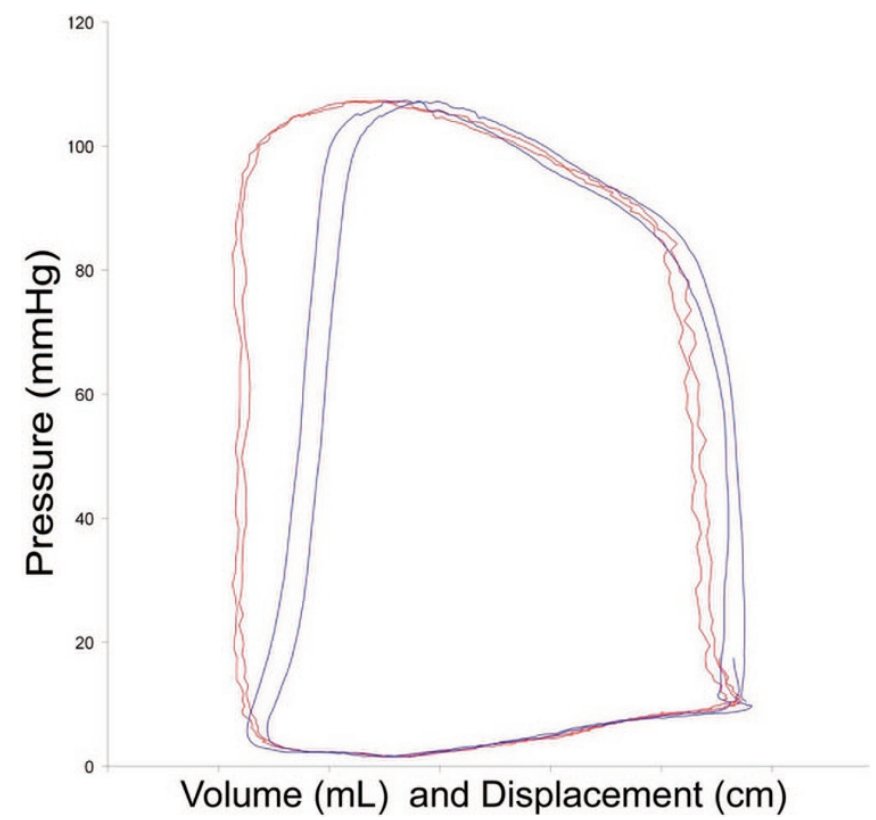

Figure 4. Longitudinal contribution to stroke work. Pressure-displacement loops from two consecutive cardiac cycles (blue lines) are compared with two simultaneous pressure-volume loops (red lines). Volume and $D$ are scaled in the ratio 1:11.

between PSF and $S^{\prime}$. Despite an increase in $E_{\mathrm{a}}, \mathrm{SV} / D$ and PSF $/ S^{\prime}$ did not change during this challenge.

Replacing PSF and $S V$ with $\mathbf{S}^{\prime}$ and $\mathrm{D}$. Figure 3 shows only minor variations from beat-to-beat enhancing the representative value of longitudinal tissue $D$ as a surrogate for SV. Furthermore, tissue velocity and flow followed similar trajectories. A loop of pressure-displacement was constructed in a similar fashion to that of the well-known pressure-volume loops. A pressure-displacement loop displayed together with the pressure-volume loop exemplifies the amount of SW (area of the loop) that is contributed to by $D$ in the long axis (Fig. 4).

\section{DISCUSSION}

This study shows how systolic velocity represents longitudinal contribution to systolic flow, while systolic longitudinal $D$ represents the contribution to SV. The link between $D$ and $\mathrm{SV}$ is well known, but some controversies regarding absolute contribution exist (7-10). In this study, the longitudinal contribution to PSF and SV was relative stable through both pharmacological and HR modulation and during modulation of the loading state of the ventricle. This was underlined by minor changes in the PSF/ $S^{\prime}$ ratio and SVID ratio only. The importance of this finding is supported by the evolving importance of the longitudinal function in the adult population (11-13). Our data support the prominent contribution of the long axis to cardiac ejection by the close relation and cross correlation of the respective curves (Figs 2 and 3). This may not be uniform with increasing body size, and the short axis function may be more prominent in smaller individuals (14). The influence of afterload on $S^{\prime}$ was evident and in keeping with others (15-17).

Our data are somewhat in contrast to the extensive tissue Doppler data of Eidem et al.(18) which include data from infancy to adolescence. Although a negative correlation between $S^{\prime}$ and HR and a positive correlation between $S^{\prime}$ and left ventricular end-diastolic diameter are established in this study, our data suggest PSF to be the most important determinant of $S^{\prime}$. Hence, $S^{\prime}$ increases with HR when SV is kept constant and vice versa. Table 2 shows the effects of pacing on the hemodynamics. The between-individuals data in Eidem et al. study are in contrast to the within-individuals data in our study. One explanation is in the different allometric scaling of HR and SV during growth (14). HR decreases with age, while SV increases. The netto effect is, however, an increase in PSF and $S^{\prime}$. Hence, regarding our data, $S^{\prime}$ increases with PSF which increases with age. The same applies to the comparison of $S^{\prime}$ between neonates and children (19). In this way, our data contribute to the understanding of changes in tissue Doppler velocity and displacement among and within individuals.

The normalized correlation coefficients showed a very close correlation for longitudinal $D$ compared with SV, with an overall fit of more than $90 \%$. This was lower, but still above $80 \%$, for longitudinal tissue Doppler velocities compared with PSF. The reason for the different correlation between $S^{\prime}$ and PSF and $D$ and SV could be different signal to noise ratios. The best fit was found between $D$ and volume, which both have a high signal to noise ratio, while derivation of the volume signal decreases the signal to noise ratio for PSF. On the other hand, the lack of a perfect fit between the PSF and tissue velocity curve needs to be explained (Fig. 2). The lack of fit between the two curves suggests that contributors, other than the long axis, support PSF during systolic contraction. Short-axis contribution to PSF is probably one of the main reasons for the lack of fit, and simultaneous tissue Doppler 
curves of both short and long axis should be scaled and merged to fit the true ventricular flow curve, to understand the contribution of both. Because radial and longitudinal contribution to PSF may change during the cardiac cycle and respond different to loading conditions, the assessment of this relationship may be difficult. Oki et al. (20) have shown that afterload may influence short axis velocity less than longitudinal velocity during early systole, while this relationship changes during late systole.

The newborn pigs in this study ranged from 2.5 to more than $6 \mathrm{~kg}$. Positive correlations were found between heart weight and SV, and even stronger between heart weight and $D$. This indicates that the validity of $D$ representing SV during rapid growth in the neonatal period holds true. Furthermore, this indicates that $D$ is nonlinearily related to age in the same way as SV and heart weight. The key to the understanding of the relationship between tissue Doppler data and body size is to be found in allometric scaling laws (14).

To extrapolate the relatively constant relations between PSF and $S^{\prime}, \mathrm{SV}$ and $D$ onto the general population is probably not appropriate at this stage, because of dissimilarities between the human and porcine heart and should be further evaluated in humans. Heart size and SV are determined by body size (21). SV scales allometrically to body size by a power of 1.5 (22). The scaling of $D$ toward SV and body size could be influenced by a change in the dominance of the longitudinal function with growth. Scaling of $D$ and SV with growth or heart size is therefore important to assess $(23,24)$. Because both SV and ET scales differently to body size, the different impact of ET and SV on $S^{\prime}$ may change during developmental growth $(14,25,26)$. ET is determined mainly by HR and inotropic state (27-29). ET and cardiac output are likewise scaled to body size, indicating the importance of body size as an important determinant of $S^{\prime}(14,25)$. Therefore, the effect of ET, SV, and inotropic state on $S^{\prime}$ is important to consider in children at different ages. This interplay between the hemodynamic variables is well documented in the afterload challenge (Table 4). As afterload increases; inotropy, represented by $\mathrm{dP} / \mathrm{d} t_{\max }$, increases (Anrep effect), $\mathrm{SV}$ decreases and ET increases, while $S^{\prime}$ decreases. An increase in $\mathrm{dP} / \mathrm{d} t_{\max }$ would normally increase PSF and hence $S^{\prime}$, while increased afterload would reduce myocardial contraction velocity $(16,30)$. Although PSF was relatively stable in our experiment, PSF and $E_{\mathrm{a}}$ were found to be the most important determinants of $S^{\prime}$ during afterload increase. SV reduction during aortic occlusion was associated with a reduction in $S^{\prime}$, despite an increase in $\mathrm{dP} / \mathrm{d} t_{\max }$ and $E_{\mathrm{a}}$. PSF and the ratio between PSF and $S^{\prime}$ did not change during afterload increase. For preload reduction, the pattern is different (Table 3); ET decreases, LVP, $\mathrm{dP} / \mathrm{d} t_{\max }$ and SV decreases. PSF and LVP are found to be the main determinants of $S^{\prime}$ during preload reduction. This shows that in individuals of similar body size, $S^{\prime}$ changes in accordance with PSF, which again is determined by SV, ET, and inotropic state (Table 2), while $S^{\prime}$ and $D$ are expected to change with heart size. The hemodynamic responses to pharmacology and pacing seen in this study are comparable with that of others (31).

In conclusion, this study provides validity of accounting systolic displacement $(D)$ in the long axis as the longitudinal contribution to stroke volume (SV) and peak systolic tissue velocity $\left(S^{\prime}\right)$ as the longitudinal contribution to peak systolic flow (PSF).

Acknowledgments. The authors thank Roger Ødegaad, Thomas N. Alme, and Grete A.B. Kro for technical assistance during the experiments and Are H. Pripp for valuable help with statistical modeling.

\section{REFERENCES}

1. Arce OX, Knudson OA, Ellison MC, Baselga P, Ivy DD, Degroff C, Valdes-Cruz L 2002 Longitudinal motion of the atrioventricular annuli in children: reference values, growth related changes, and effects of right ventricular volume and pressure overload. J Am Soc Echocardiogr 15:906-916

2. Carlsson M, Ugander M, Mosen H, Buhre T, Arheden H 2007 Atrioventricular plane displacement is the major contributor to left ventricular pumping in healthy adults, athletes, and patients with dilated cardiomyopathy. Am J Physiol Heart Circ Physiol 292:H1452-H1459

3. Gjesdal O, Vartdal T, Hopp E, Lunde K, Brunvand H, Smith HJ, Edvardsen T 2009 Left ventricle longitudinal deformation assessment by mitral annulus displacement or global longitudinal strain in chronic ischemic heart disease: are they interchangeable? J Am Soc Echocardiogr 22:823-830

4. Friedberg MK, Mertens L 2009 Tissue velocities, strain, and strain rate for echocardiographic assessment of ventricular function in congenital heart disease. Eur J Echocardiogr 10:585-593

5. Steendijk P, Staal E, Jukema JW, Baan J 2001 Hypertonic saline method accurately determines parallel conductance for dual-field conductance catheter. Am J Physiol Heart Circ Physiol 281:H755-H763

6. Sullivan LM 2008 Repeated measures. Circulation 117:1238-1243

7. Qin JX, Shiota T, Tsujino H, Saracino G, White RD, Greenberg NL, Kwan J, Popovic ZB, Agler DA, Stewart WJ, Thomas JD 2004 Mitral annular motion as a surrogate for left ventricular ejection fraction: real-time three-dimensional echocardiography and magnetic resonance imaging studies. Eur J Echocardiogr 5:407-415

8. Ballo P, Bocelli A, Mondillo S 2007 What is the actual contribution of atrioventricular plane displacement to left ventricular stroke volume? Am J Physiol Heart Circ Physiol 293:H1315

9. Urheim S, Cauduro S, Frantz R, McGoon M, Belohlavek M, Green T, Miller F, Bailey K, Seward J, Tajik J, Abraham TP 2005 Relation of tissue displacement and strain to invasively determined right ventricular stroke volume. Am J Cardiol 96:1173-1178

10. Carlhäll C, Wigström L, Heiberg E, Karlsson M, Bolger AF, Nylander E 2004 Contribution of mitral annular excursion and shape dynamics to total left ventricular volume change. Am J Physiol Heart Circ Physiol 287:H1836-H1841

11. Sanderson JE $2008 \mathrm{Left}$ and right ventricular long-axis function and prognosis. Heart 94:262-263

12. Sveälv BG, Olofsson EL, Andersson B 2008 Ventricular long-axis function is of major importance for long-term survival in patients with heart failure. Heart 94:284289

13. Mogelvang R, Sogaard P, Pedersen SA, Olsen NT, Marott JL, Schnohr P, Goetze JP, Jensen JS 2009 Cardiac dysfunction assessed by echocardiographic tissue Doppler imaging is an independent predictor of mortality in the general population. Circulation 119:2679-2685

14. Popović ZB, Sun JP, Yamada H, Drinko J, Mauer K, Greenberg NL, Cheng Y, Moravec CS, Penn MS, Mazgalev TN, Thomas JD 2005 Differences in left ventricular long-axis function from mice to humans follow allometric scaling to ventricular size. J Physiol 568:255-265

15. Borlaug BA, Melenovsky V, Redfield MM, Kessler K, Chang HJ, Abraham TP, Kass DA 2007 Impact of arterial load and loading sequence on left ventricular tissue velocities in humans. J Am Coll Cardiol 50:1570-1577

16. Daniels M, Noble MI, ter Keurs HE, Wohlfart B 1984 Velocity of sarcomere shortening in rat cardiac muscle: relationship to force, sarcomere length, calcium and time. J Physiol 355:367-381

17. Kuo AS, Sato H, Reoma JL, Cook KE 2009 The relationship between pulmonary system impedance and right ventricular function in normal sheep. Cardiovasc Eng 9:153-160

18. Eidem BW, McMahon CJ, Cohen RR, Wu J, Finkelshteyn I, Kovalchin JP, Ayres NA, Bezold LI, O'Brian SE, Pignatelli RH 2004 Impact of cardiac growth on Doppler tissue imaging velocities: a study in healthy children. J Am Soc Echocardiogr 17:212-221

19. Ekici F, Atalay S, Ozcelik N, Ucar T, Yilmaz E, Tutar E 2007 Myocardial tissue velocities in neonates. Echocardiography 24:61-67

20. Oki T, Fukuda K, Tabata T, Mishiro Y, Yamada H, Abe M, Onose Y, Wakatsuki T, Iuchi A, Ito S 1999 Effect of an acute increase in afterload on left ventricular regional wall motion velocity in healthy subjects. J Am Soc Echocardiogr 12:476-483

21. de Simone G, Devereux RB, Daniels SR, Mureddu G, Roman MJ, Kimball TR, Greco R, Witt S, Contaldo F 1997 Stroke volume and cardiac output in normotensive children and adults: assessment of relations with body size and impact of overweight. Circulation 95:1837-1843 
22. Gutgesell HP, Rembold CM 1990 Growth of the human heart relative to body surface area. Am J Cardiol 65:662-668

23. Grüner Sveälv B, Fritzon G, Andersson B 2006 Gender and age related differences in left ventricular function and geometry with focus on the long axis. Eur J Echocardiogr 7:298-307

24. Batterham A, Shave R, Oxborough D, Whyte G, George K 2008 Longitudinal plane colour tissue-Doppler myocardial velocities and their association with left ventricular length, volume, and mass in humans. Eur J Echocardiogr 9:542-546

25. West GB, Brown JH, Enquist BJ 1997 A general model for the origin of allometric scaling laws in biology. Science 276:122-126

26. Emilsson K, Alam M, Wandt B 2000 The relation between mitral annulus motion and ejection fraction: a nonlinear function. J Am Soc Echocardiogr 13:896-901
27. Spitaels S, Arbogast R, Fouron JC, Davignon A 1974 The influence of heart rate and age on the systolic and diastolic time intervals in children. Circulation 49:1107-1115

28. Suga H, Sagawa K 1974 Instantaneous pressure-volume relationships and their ratio in the excised, supported canine left ventricle. Circ Res 35:117-126

29. Cantor A, Wanderman KL, Karolevitch T, Ovsyshcher I, Gueron M 1978 Systolic time intervals in children: normal standards for clinical use. Circulation 58:11231129

30. Lyseggen E, Rabben SI, Skulstad H, Urheim S, Risoe C, Smiseth OA 2005 Myocardial acceleration during isovolumic contraction: relationship to contractility. Circulation 111:1362-1369

31. Shaddy RE, Tyndall MR, Teitel DF, Li C, Rudolph AM 1988 Regulation of cardiac output with controlled heart rate in newborn lambs. Pediatr Res 24:577-582 